Original Article

\title{
Synergistic effect of a rehabilitation program and treadmill exercise on pain and dysfunction in patients with chronic low back pain
}

\author{
Young-Ki Cho, MS, PT ${ }^{1)}$, Dae-Young Kim, PhD²), Sun-Young Jung, PhD, PT ${ }^{3)}$, \\ Jun-Hyuk Seong, MS, PT ${ }^{1)}$ \\ 1) Department of Rehabilitation Medicine, Asan Medical Center, University of Ulsan College of \\ Medicine, Republic of Korea \\ 2) Department of Sports Healthcare, Inje University: 197 Injero, Gimhae-si, Gyeongsangnam-do \\ 621-749, Republic of Korea \\ 3) Department of Physiology, College of Medicine, Kyung Hee University, Republic of Korea
}

\begin{abstract}
Purpose] The present study examined the influence of treadmill exercise added to a low back pain rehabilitation program on low back extensor strength, pain, and dysfunction in chronic low back pain patients. [Subjects and Methods] Twenty men aged 22-36 years with chronic low back pain were randomly divided into experimental and control groups of 10 patients each. Both groups underwent a low back pain rehabilitation program lasting $30 \mathrm{~min}$ each, thrice/week for 8 weeks. The experimental group was prescribed an additional $30 \mathrm{~min}$ of treadmill exercise without a slope at a speed of $3.0-3.5 \mathrm{~km} / \mathrm{h}$, at which patients could walk comfortably. Low back extensor strength was tested using the Medx lumbar extension machine, pain level was tested, using the visual analog scale, and dysfunction was tested, using the Oswestry Low Back Pain Disability Questionnaire. [Results] Changes in low back extensor strength by angle showed significant interaction effects between measurement time and group at $12^{\circ}, 24^{\circ}$, and $36^{\circ}$. The results of the visual analog scale and Oswestry Questionnaire showed a decreasing trend after the experiment in both groups. However, there was no interaction effect of the additional treadmill exercise in the experimental group. [Conclusion] The combination of a low back pain rehabilitation program and treadmill exercise has a synergistic effect, to some extent, on the improvement of low back extensor strength and should be considered for treatment and rehabilitation of low back pain patients.

Key words: Low back pain, Rehabilitation, Treadmill exercise
\end{abstract}

(This article was submitted Oct. 29, 2014, and was accepted Dec. 11, 2014)

\section{INTRODUCTION}

Over $70 \%$ of the population in developed countries experiences low back pain, and its incidence is increasing in developing countries as well; low back pain is therefore a global problem ${ }^{1)}$. As varied and complex psychological and social factors are involved, the pain has no definite cause in about $85 \%$ of patients ${ }^{2}$. Low back pain is divided into acute or chronic according to its duration; if the pain lasts for over 12 weeks, it is defined as chronic low back pain, and 5-10\% of all acute low back pain patients develop chronic low back pain $^{3)}$.

Once low back pain becomes serious, physical activities are restricted, and ultimately muscle atrophy occurs as the muscles remain unused for long durations ${ }^{4}$. Particularly in

*Corresponding author. Dae-Young Kim (E-mail: cdps21@, empas.com)

(C2015 The Society of Physical Therapy Science. Published by IPEC Inc. This is an open-access article distributed under the terms of the Creative Commons Attribution Non-Commercial No Derivatives (by-ncnd) License $<$ http://creativecommons.org/licenses/by-nc-nd/3.0/>. chronic low back pain patients, the worsening of low back pain caused by reduction in the muscle area and muscular atrophy leads to secondary damage and relapse ${ }^{5)}$. Many low back pain patients develop recurring low back pain due to lumbar instability caused by muscular weakness around the spine and soft tissue damage in the trunk. Finally, the reduction in muscular strength, muscular endurance, and flexibility in the lumbar spine and limited range of motion of joints cause relapse of chronic low back pain ${ }^{6}$. In particular, chronic low back pain patients have more severe atrophy of low back extensors than of flexors ${ }^{7}$. Additionally, the aerobic exercise capacity tends to decrease in patients with chronic low back pain owing to the limitation on motionthis must be considered in rehabilitation exercise ${ }^{8}$.

The reasons for low back pain are still under discussion, and over many years, various exercise methods have been suggested for treating low back pain, including flexion exercise, isometric flexion exercise, extension exercise, passive extension exercise, and intensive dynamic back exercise ${ }^{9,10)}$. Although these exercise programs have been recommended and developed over several years in low back pain discussions and rehabilitation centers, a satisfactory outcome has not yet emerged. Despite greatly differ- 
1188 J. Phys. Ther. Sci. Vol. 27, No. 4, 2015

Table 1. Physical characteristics of the study participants

\begin{tabular}{lcccc}
\hline Group & Age (years) & Height $(\mathrm{cm})$ & Weight $(\mathrm{kg})$ & BMI $\left(\mathrm{kg} / \mathrm{m}^{2}\right)$ \\
\hline Control $(\mathrm{N}=10)$ & $27.7 \pm 4.2$ & $170.2 \pm 9.4$ & $65.5 \pm 15.2$ & $22.3 \pm 3.4$ \\
Exercise $(\mathrm{N}=10)$ & $29.1 \pm 4.8$ & $172.5 \pm 3.7$ & $69.1 \pm 12.1$ & $23.1 \pm 3.5$ \\
\hline
\end{tabular}

Data are means \pm SD

ent opinions on the pathogenesis of low back pain among researchers, therapeutic exercise is known to be effective in genera ${ }^{11)}$. In addition, therapeutic exercise in which patients participate actively is effective for low back pain after the acute phase, and in particular, different types of exercises applied by physiotherapists show very positive outcomes ${ }^{12}$.

Rehabilitation programs for the relief of low back pain include complex exercises such as selective exercises involving control of trunk muscles, muscle strengthening, muscle stretching, and aerobic exercises ${ }^{13}$. Recent studies report that aerobic exercise is effective in reducing depression, pain, and dysfunction in low back pain patients ${ }^{14)}$. However, some studies report that aerobic exercise combined with traditional physical therapy has no additional effect on pain and dysfunction ${ }^{15}$. Therefore, there are conflicting results concerning the effects of aerobic exercise in low back pain patients, and there is also a lack of clear evidence on this matter. Therefore, the purpose of this study was to determine the additional effect of treadmill exercise combined with a low back pain rehabilitation exercise program on low back extensor strength, pain, and dysfunction in patients with chronic low back pain.

\section{SUBJECTS AND METHODS}

This study involved 20 men aged 22-36 years with chronic low back pain who visited a hospital rehabilitation medicine department; they were randomly divided into experimental group and a control group, with 10 patients in each group. Patients who complained of low back pain lasting for over 3 months were selected as subjects, and patients with musculoskeletal diseases that impaired gait, heart diseases, neurological disorders, or structural spine deformity were excluded. All the subjects of this study signed the consent form for this study voluntarily after the intent and purposes of the study were explained to them. Kyungwoon University approved this study, which complies with the ethical standards of the Declaration of Helsinki. The physical characteristics of the subjects in each group are shown in Table 1. The low back pain rehabilitation program was conducted for 30 minutes, thrice a week for 8 weeks for the control and experimental groups. The program consisted of 14 exercises including flexion and extension, and it was conducted under the continuous guidance and supervision of an expert in a low back pain treatment room. The experimental group performed an additional 30 min of treadmill exercise. Treadmill exercise was conducted without a slope at a speed of $3.0-3.5 \mathrm{~km} / \mathrm{h}$, which allowed patients to walk comfortably, and the patients were instructed to straighten their back and make initial contact with their heel.

For the low back extensor strength test, the Medx ${ }^{\mathrm{TM}}$ lumbar extension machine (H-10000; MedX, Ocala, FL, USA) was used, and measurement were taken before and after the experiment for both groups. Before starting the low back extensor strength test, the tester moved the machine manually and conducted the range of motion (ROM) exercise 3 times to check that there were no limitations in ROM at the designated degree of flexion for the lumbar spine. The test was conducted to measure the maximum isometric torque of the lumbar spine extensors according to degree of flexion $\left(72^{\circ}, 60^{\circ}, 48^{\circ}, 36^{\circ}, 24^{\circ}, 12^{\circ}, 0^{\circ}\right)$ starting from the $72^{\circ}$ position (Table 2).

To evaluate the level of low back pain in the patient group, the visual analog scale (VAS) was used. On a 10-cmlong horizontal straight line with "No pain" and "Very severe pain" written on the left and right end respectively, the patients marked the pain intensity they were currently feeling directly with a pen.

The Oswestry Low Back Pain Disability Questionnaire was developed by Fairbank et al. ${ }^{16)}$ to measure the relief and aggravation of the symptoms of low back pain patients. In this study, a revised questionnaire was used ${ }^{17)}$, and this tool consisted of a total of 10 detailed questions concerning such things as low back pain intensity, self-management, lifting motion, sitting, standing, sleeping, social life, traveling, and job performance. For each question, a 6-point scale was provided for scoring the functional performance ability. The total number of points given ranges from a maximum of 60 points to a minimum of 10 points, and the higher the score, the more severe the dysfunction.

Two-way repeated measure analysis of variance (ANOVA) was conducted for all data analyses in order to express the average and standard deviation values and to test the group trends before and after the exercise program. Comparisons of changes in the average values of measurement variables before and after the 8-week exercise program were analyzed using the paired samples t-test. In addition, the variation $(\Delta)$ between baseline measurements and measurements after 8 weeks of exercise was calculated $(\Delta$ score $=$ changed score between before and after 8 weeks of exercise). All statistical analyses were conducted using the PC version of the Statistical Package for the Social Sciences (SPSS version 21.0; IBM Corporation, Armonk, NY, USA), and statistical significance was set at $\mathrm{p}<0.05$.

\section{RESULTS}

According to angle, the changes in low back extensor strength showed significant interaction effects of measurement time and group at $12^{\circ}(\mathrm{p}=0.034), 24^{\circ}(\mathrm{p}=0.029)$, and $36^{\circ}(\mathrm{p}=0.011)$. However, at $48^{\circ}, 60^{\circ}$, and $72^{\circ}$, both the control group and experimental group showed no interaction effect despite showing an increasing trend in low back extensor strength after the experiment compared with before 
Table 2. Comparison of the average change in low back extensor strength between both groups

\begin{tabular}{clrll}
\hline Degree & Group & \multicolumn{1}{c}{ Pre-test } & \multicolumn{1}{c}{ Post-test } & \multicolumn{1}{c}{$\Delta$ score } \\
\hline \multirow{2}{*}{$0^{\circ}$} & Control & $97.3 \pm 59.2$ & $130.6 \pm 73.4$ & $33.3 \pm 28.2$ \\
& Exercise & $99.1 \pm 59.6$ & $141.5 \pm 60.2$ & $42.4 \pm 30.1^{* * *}$ \\
\multirow{2}{*}{$12^{\circ}$} & Control & $130.3 \pm 77.6$ & $157.6 \pm 80.7$ & $27.3 \pm 24.2$ \\
& Exercise & $125.1 \pm 57.4$ & $179.6 \pm 60.9^{\dagger}$ & $54.5 \pm 28.6^{* * *}$ \\
$24^{\circ}$ & Control & $148.3 \pm 81.7$ & $181.2 \pm 80.9$ & $32.9 \pm 28.4$ \\
& Exercise & $146.8 \pm 64.6$ & $214.2 \pm 52.1^{\dagger}$ & $67.4 \pm 36.0^{* * *}$ \\
$36^{\circ}$ & Control & $166.7 \pm 83.4$ & $198.6 \pm 86.6$ & $31.9 \pm 19.6$ \\
& Exercise & $157.9 \pm 63.7$ & $220.8 \pm 51.4^{\dagger}$ & $62.9 \pm 28.1^{* * *}$ \\
$48^{\circ}$ & Control & $183.1 \pm 87.7$ & $218.0 \pm 96.6$ & $34.9 \pm 25.8$ \\
& Exercise & $174.9 \pm 62.6$ & $233.6 \pm 57.6$ & $58.7 \pm 30.8^{* * *}$ \\
$60^{\circ}$ & Control & $203.4 \pm 97.4$ & $240.9 \pm 107.8$ & $37.5 \pm 31.4$ \\
& Exercise & $189.1 \pm 66.1$ & $247.9 \pm 61.9$ & $58.8 \pm 25.5^{* * *}$ \\
$72^{\circ}$ & Control & $214.5 \pm 10.9$ & $257.2 \pm 113.6$ & $42.7 \pm 27.2$ \\
& Exercise & $208.2 \pm 73.9$ & $258.6 \pm 67.3$ & $50.4 \pm 37.5^{* * *}$ \\
\hline
\end{tabular}

Data are means \pm SD. $\Delta$ score $=$ change in score. Paired t-test: ${ }^{*} \mathrm{p}<0.05 ;{ }^{*} \mathrm{p}<0.01$;

${ }^{* * *} \mathrm{p}<0.001$. Two-way ANOVA test (group $\times$ time): ${ }^{\dagger} \mathrm{p}<0.05 ;{ }^{\dagger \dagger} \mathrm{p}<0.01 ;{ }^{\dagger \dagger} \mathrm{p}<0.001$ )

Table 3. Changes in the visual analog scale and Oswestry Low Back Pain Disability Scores

\begin{tabular}{llccc}
\hline Variable & Group & Pre-test & Post-test & $\Delta$ score \\
\hline \multirow{2}{*}{ VAS } & Control & $36.3 \pm 17.4$ & $20.5 \pm 13.1$ & $-15.8 \pm 13.5$ \\
& Exercise & $31.3 \pm 17.9$ & $16.9 \pm 9.3$ & $-14.4 \pm 12.3^{* *}$ \\
Oswestry & Control & $16.5 \pm 3.5$ & $14.4 \pm 5.0$ & $-2.1 \pm 3.0$ \\
questionnaire & Exercise & $14.9 \pm 3.0$ & $11.7 \pm 1.7$ & $-3.2 \pm 2.0^{* * *}$ \\
\hline
\end{tabular}

Data are means \pm SD. $\Delta$ score $=$ change in score, Paired t-test: ${ }^{*} \mathrm{p}<0.05 ;{ }^{* *} \mathrm{p}<0.01 ;{ }^{* * *} \mathrm{p}<0.001$. Two-way ANOVA test (group $\times$ time): ${ }^{\dagger} p<0.05 ;{ }^{\dagger} p<0.01,{ }^{\dagger \dagger} p<0.001$. VAS: visual analog scale, Oswestry questionnaire: Oswestry Low Back Pain Disability Questionnaire

the experiment.

The VAS and Oswestry Low Back Pain Disability Questionnaire scores showed a decreasing trend after the experiment compared with before the experiment, both in the control group and the experimental group. However, there was no interaction effect of the additional treadmill exercise in the experimental group compared to the control group (Table 3 ).

\section{DISCUSSION}

Low back pain is one of the most widespread diseases in modern society. Rapid economic development and a sedentary lifestyle have brought about a reduction in physical activity and changes in physical function and posture, leading to the incidence of low back pain. In most low back pain patients, muscular weakness and imbalance around the lumbar spine caused by lack of exercise are the major factors that cause activity impairment. This is because muscular weakness and imbalance lead to low back pain, and this pain limits the range of motion and prevents the proper exertion of muscular strength. Generally, low back pain patients reduce their physical activity to avoid the pain caused during the performance of their daily routine activities ${ }^{18)}$, leading to a vicious circle of relapse and chronicization of low back pain, which in turn reduces aerobic exercise capacity (cardiorespiratory fitness $)^{19)}$. The reduction of activities of daily living (ADL) after the occurrence of low back pain causes sarcopenia and reduces muscular strength, muscular endurance, and cardiopulmonary function, leading to an increase in the likelihood of development of metabolic risk factors ${ }^{20}$. Therefore, performing aerobic exercise to improve low back extensor strength is important. In this study, additional treadmill exercise was conducted by patients performing a low back pain rehabilitation program for 8 weeks to determine if the addition of this exercise was effective.

In this study, changes in low back extensor strength showed a significant interaction effect by angle at $12^{\circ}, 24^{\circ}$, and $36^{\circ}$, which was considered to be the effect of the treadmill exercise conducted under the supervision of experts who ensured that the patients performed the exercise with their backs straight and made initial contact with their heel. In other words, low back extensors are activated and muscular strength increases by walking properly and improving lordosis; these findings are attributed to the effect of training the supporting muscles involved in the angle changes of extensors often used in the lumbar region when performing walking exercises.

Kankaanpää et al. ${ }^{21)}$ found that the low back extensors of chronic low back pain patients were weak and got easily 
tired as compared with those of normal people. Lamoth et al. ${ }^{22)}$ concluded that walking training should be considered in rehabilitation programs for chronic low back pain patients, since the stability between their lumbar sections was low and the coordination between the low back extensors was poor. From a rehabilitative perspective, it can be said that walking programs are helpful for simultaneously stabilizing the trunk and controlling the motion of the limbs by strengthening the waist muscles and abdominal muscles supporting the spine.

In this study, the VAS and Oswestry Low Back Pain Disability Questionnaire scores of the experimental group showed no interaction effect of the additional treadmill exercise as compared with those of the control group. Tritilanunt et al. ${ }^{23)}$ found that chronic low back pain patients that performed an aerobic exercise program for 3 months showed a significantly reduced pain index compared with those who performed only lumbar flexion exercise. Also, Chatzitheodorou et al. ${ }^{14)}$ found that chronic low back pain patients that performed high-intensity aerobic exercise for 12 weeks showed significantly reduced pain, dysfunction, and psychological burdens compared with those who received only conservative physical therapy. However, Chan et al. ${ }^{15)}$ found that aerobic exercise combined with an 8-week physical therapy had no additional effect on the alleviation of pain and dysfunction, similar to the findings of this study. The lack of an additional effect of treadmill exercise in this study is attributed to the fact that both groups underwent back mobilization, performed abdominal stabilization exercise, and received back care advice based on ergonomic principles in addition to traditional physical therapy. However, as many studies have reported an additional effect of aerobic exercise, further systematic long-term studies with many subjects are required to confirm the findings of the present study.

Considering all the outcomes of this study, the changes in low back extensor strength by angle showed an additional effect of treadmill exercise at $12^{\circ}, 24^{\circ}$, and $36^{\circ}$, and pain level and dysfunction index showed a decreasing trend after the experiment in both groups, with no significant difference between groups. It is thought that treadmill exercise combined with traditional physical therapy has a partial effect on improvement of low back extensor strength.

\section{REFERENCES}

1) Huang Q, Zhang Y, Li D, et al.: The evaluation of chronic low back pain by determining the ratio of the lumbar multifidus muscle cross-sectional areas of the unaffected and affected sides. J Phys Ther Sci, 2014, 26: 1613-1614 [Medline] [CrossRef]

2) Santos FG, Carmo CM, Fracini AC, et al.: Chronic low back pain in women: muscle activation during task performance. J Phys Ther Sci, 2013, 25: 1569-1573. [Medline] [CrossRef]
3) Airaksinen O, Brox JI, Cedraschi C, et al. COST B13 Working Group on Guidelines for Chronic Low Back Pain: Chapter 4. European guidelines for the management of chronic nonspecific low back pain. Eur Spine J, 2006, 15: S192-S300. [Medline] [CrossRef]

4) Polatin P: The functional restoration approach to chronic low back pain. J Musculoskelet Med, 1990, 7: 17-30.

5) Pecak F, Trontelj JV, Dimitrijevic MR: Scoliosis in neuromuscular disorders. Int Orthop, 1980, 3: 323-328. [Medline] [CrossRef]

6) Jemmett R: Spinal stabilization the new science of back pain. Novont Health Publ, 2003, 24: 37-63.

7) Beimborn DS, Morrissey MC: A review of the literature related to trunk muscle performance. Spine, 1988, 13: 655-660. [Medline] [CrossRef]

8) Smeets RJ, van Geel KD, Verbunt JA: Is the fear avoidance model associated with the reduced level of aerobic fitness in patients with chronic low back pain? Arch Phys Med Rehabil, 2009, 90: 109-117. [Medline] [CrossRef

9) McKenzie RA: Prophylaxis in recurrent low back pain. N Z Med J, 1979, 89: 22-23. [Medline]

10) Manniche $C$, Lundberg E, Christensen I, et al.: Intensive dynamic back exercises for chronic low back pain: a clinical trial. Pain, 1991, 47: 53-63. [Medline] [CrossRef]

11) Carpenter DM, Nelson BW: Low back strengthening for the prevention and treatment of low back pain. Med Sci Sports Exerc, 1999, 31: 18-24. [Medline] [CrossRef]

12) van Tulder M, Malmivaara A, Esmail R, et al.: Exercise therapy for low back pain: a systematic review within the framework of the cochrane collaboration back review group. Spine, 2000, 25: 2784-2796. [Medline] [CrossRef]

13) Moseley L: Combined physiotherapy and education is efficacious for chronic low back pain. Aust J Physiother, 2002, 48: 297-302. [Medline] [CrossRef]

14) Chatzitheodorou D, Kabitsis C, Malliou P, et al.: A pilot study of the effects of high-intensity aerobic exercise versus passive interventions on pain, disability, psychological strain, and serum cortisol concentrations in people with chronic low back pain. Phys Ther, 2007, 87: 304-312. [Medline] [CrossRef]

15) Chan CW, Mok NW, Yeung EW: Aerobic exercise training in addition to conventional physiotherapy for chronic low back pain: a randomized controlled trial. Arch Phys Med Rehabil, 2011, 92: 1681-1685. [Medline] [CrossRef]

16) Fairbank JC, Couper J, Davies JB, et al.: The Oswestry low back pain disability questionnaire. Physiotherapy, 1980, 66: 271-273. [Medline]

17) Fritz JM, Irrgang JJ: A comparison of a modified Oswestry Low Back Pain Disability Questionnaire and the Quebec Back Pain Disability Scale. Phys Ther, 2001, 81: 776-788. [Medline]

18) Picavet HS, Schuit AJ: Physical inactivity: a risk factor for low back pain in the general population? J Epidemiol Community Health, 2003, 57: $517-$ 518. [Medline] [CrossRef]

19) Verbunt JA, Seelen HA, Vlaeyen JW, et al.: Disuse and deconditioning in chronic low back pain: concepts and hypotheses on contributing mechanisms. Eur J Pain, 2003, 7: 9-21. [Medline] [CrossRef]

20) Kim DY, Jung SY, Seo BD: Effect of exercise intervention on changes in free Fatty Acid levels and metabolic risk factors in stroke patients. J Phys Ther Sci, 2014, 26: 275-279. [Medline] [CrossRef]

21) Kankaanpää $M$, Taimela $S$, Laaksonen $D$, et al.: Back and hip extensor fatigability in chronic low back pain patients and controls. Arch Phys Med Rehabil, 1998, 79: 412-417. [Medline] [CrossRef]

22) Lamoth CJ, Daffertshofer A, Meijer OG, et al.: Effects of experimentally induced pain and fear of pain on trunk coordination and back muscle activity during walking. Clin Biomech (Bristol, Avon), 2004, 19: 551-563. [Medline] [CrossRef]

23) Tritilanunt $T$, Wajanavisit $W$ : The efficacy of an aerobic exercise and health education program for treatment of chronic low back pain. J Med Assoc Thai, 2001, 84: S528-S533. [Medline] 